\title{
Violet-blue light exposure of the skin: is there need for protection?
}

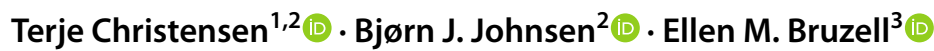

Received: 3 December 2020 / Accepted: 8 April 2021 / Published online: 24 April 2021

(c) The Author(s) 2021

\begin{abstract}
Advocates of skin protection against blue light express concern about exposure to indoor lighting and electronic screens as well as natural outdoor exposure. However, the nature of adverse effects in skin is unclear and the doses to induce effects are unknown. We aimed to reveal whether there is a scientific basis for promoting skin protection against violet-blue light (400-500 nm, VBL). Based on published literature, we determined the time to reach a threshold dose that induced a biological response in human skin. In the absence of an action spectrum for effects on skin, we used a hand held probe with a defined spectral response and measurements of the unweighted exposure between 400 and $500 \mathrm{~nm}$ to estimate the exposure by a selection of artificial light sources and solar light. For comparison, an outdoor threshold erythemally weighted UV dose was set to 1 SED (standard erythema dose). Outdoor, weighted irradiances were obtained using a radiative transfer model. Induction of pigmentation in human skin tissue was the only consistently reported endpoint after VBL exposure of about 65 $\mathrm{Jcm}^{-2}$. This threshold dose was reached in 0.5 to 20 months of exposure to indoor lighting sources. In comparison, specialised medical sources reached this dose in $0.5 \mathrm{~min}$ to $45 \mathrm{~h}$. The time outdoors to reach $1 \mathrm{SED}$ was shorter than the time to reach a VBL threshold dose throughout all seasons. Skin protection against VBL is superfluous for exposures to domestic lighting sources or screens and for solar radiation; however, it may be advantageous for patients suffering from photosensitive diseases or taking photosensitising medication.
\end{abstract}

Keywords Visible light $\cdot$ Ultraviolet radiation $\cdot$ Skin aging $\cdot$ Skin pigmentation $\cdot$ Radiation dose $\cdot$ Sunscreen

\section{Introduction}

Recent academic and commercial concern expressed about adverse effects in the skin from violet and blue light (VBL) exposure goes beyond the well-known effects of ultraviolet radiation (UV) [1-4]. The focus on VBL effects [5, 6] may have contributed to the emergence of new cosmetic products for visible light protection of the skin [1]. Light sources of concern are typically indoor lighting, electronic screens and the sun. Advocates of visible light protection are in favour of widening the protection spectrum of sunscreens [7] and to develop appropriate test methods for such products $[8$, 9]. Allegedly, the concern about biological effects due to the violet-blue part of the spectrum resulted in a new term

Terje Christensen

terje.christensen222@gmail.com

1 University of South-Eastern Norway, Drammen, Norway

2 Norwegian Radiation and Nuclear Safety Authority (DSA), Østerås, Norway

3 Nordic Institute of Dental Materials (NIOM), Oslo, Norway to denote the wavelength range between 400 and $500 \mathrm{~nm}$, namely the expression "high energy visible light" (HEV) that may indicate a particular risk connected with the energy of photons in this wavelength range.

The relative spectral effectiveness for skin damage by UVA (UV with wavelengths $315 \mathrm{~nm}$ to $400 \mathrm{~nm}$ ) is from two to three orders of magnitude lower than by UVB (UV with wavelengths $280 \mathrm{~nm}$ to $315 \mathrm{~nm}$ )[10]. The spectral effectiveness is not likely to be higher in the visible than in the UVA wavelength range. On the other hand, the solar visible light irradiance at the Earth's surface is at least eight times higher than the corresponding UV irradiance (provided a solar zenith angle (SZA) of $40^{\circ}$ ).

On one hand, historically, visible light has been considered unimportant as a causative agent for effects on the skin, such as skin aging [11-13], except in the presence of exogenous or endogenous photosensitisers. On the other hand, immediate pigment darkening is recognised as a visible light effect. First reported by Hausser in 1938, pigment darkening was shown to appear as result of a broad range of wavelengths in the visible by Pathak and colleagues in 
1962 (see [14] and references therein). The same authors also described other pigment changes in the skin by UV and visible radiation. The fact that photosensitive diseases and photosensitisation by chemical substances lower the tolerance to visible light has been well known for a century [15]. More recent studies [16-20] elaborate on effects of visible light on normal skin.

Unlike solar radiation, The International Agency for Research on Cancer (IARC) does not classify fluorescent lighting as carcinogenic to humans [21]. Since visible light can be absorbed in the skin and may affect connective tissues and pigmented cells, it is likely that certain exposure levels may influence appearance and structure in terms of reduced elasticity and change in pigmentation. Since several of the mechanisms of damage by VBL are different from those caused by UV, the requirements for visible light-protecting sunscreens will be different from those set, e.g., for testing, in current standards. In the absence of a hazard function for skin and because hand-held radiometers with blue light safety sensors (response in the $400-500 \mathrm{~nm}$ range) are available, we chose to apply a sensor with a response resembling the blue light retinal hazard function $\mathrm{B}(\lambda)$ [22]. This function was used in an exposure scenario as a proxy to compare the effects of VBL emitted from a variety of light sources, without indicating any similarities in responses to VBL between the skin and the eye.

Aims of our study were

- to quantify exposure to VBL from selected sources applied for lighting, medical procedures as well as from the sun

- to compare the levels with literature values shown to induce effects in the skin

- to estimate a maximum exposure time for VBL to avoid possible adverse effects

- to compare the VBL maximum exposure time of solar radiation with the corresponding maximum value of erythemal UV

- to address the question of whether protection of the skin against VBL may be appropriate and if so, for which population groups and conditions.

\section{Methods}

\subsection{Action spectra}

The following action spectra were applied to obtain relevant radiometric and photometric values: $B(\lambda)$ [22] (proxy) to obtain blue light hazard weighted-irradiance and radiant exposure, $E_{\mathrm{b}}$ and $H_{\mathrm{b}}$, respectively, the CIE erythemal action spectrum, $S(\lambda)$ [23] to calculate the standard erythema dose (SED) and erythemally effective irradiance, $E_{\mathrm{er}}$; the photopic luminosity response of the human eye, $V(\lambda)$ [24] to calculate illuminance, $\mathrm{E}_{\mathrm{V}}$. To validate the application of the weighting function $B(\lambda)$, total spectral irradiance integrated over the wavelength interval $400-500 \mathrm{~nm}\left(E_{400-500}\right.$, without the application of a weighting function) was calculated and compared to the weighted dose products.

\subsection{Laboratory measurement of source characteristics}

A selection of five fluorescent lamp systems and one LED (light emitting diode)-based, typically found in ceiling- and wall luminaires of offices and homes, as well as nine LEDbased dental material photocuring devices were spectrally characterised. Measurements were performed with a double monochromator spectroradiometer (model DTM300, Bentham Instruments Ltd., Reading, UK) scanning the wavelength interval $250-800 \mathrm{~nm}$ (full width at half maximum (FWHM) $0.8 \mathrm{~nm}$ ). The use of an adaptively regulated filter wheel with a set of neutral density filters as well as a bi-alkaline photomultiplier tube and a silicon photodiode, connected to the spectroradiometer output ports, ensured high dynamic range and linear performance over the full spectral range.

For practical reasons, luminaires and fluorescent tubes were measured with the front optic of the spectroradiometer at a distance of $10 \mathrm{~cm}$ from the surface or front cover. A Bentham D7 transmission diffuser coupled to a lightguide provided cosine-corrected measurements for the full wavelength range (200-1100 $\mathrm{nm}$ ).

LED-based photocuring devices were measured with their light guide underfilling the opening of the spectroradiometer's fiberoptically connected integrating sphere, providing measurements in units of spectral flux and exitance. The integrating sphere was custom made by Bentham (inline input/exit port; diameter $100 \mathrm{~mm}$; baffled at the exit port; Spectralon ${ }^{\circledR}$ coating).

Irradiance calibrations were performed with a set of $1 \mathrm{~kW}$ quartz-tungsten halogen lamps, traceable to the Physikalisches Technisches Bundesanstalt (PTB) via PhysikalischMeteorologisches Observatorium Davos/World Calibration Centre (PMOD-WRC; Davos, Switzerland). The wavelength scale was calibrated against low-pressure spectral lamps. The UV irradiance scale of the Bentham DTM agreed to within $\pm 3 \%$ of a European travelling reference spectroradiometer [25]. Expanded uncertainty of Bentham VBL lamp/ lamp system measurements was estimated to $4.5 \%$ (95\% confidence interval).

One of the LED-based dental material photocuring devices was characterised using a CCD (charge-coupled devise)-based spectrometer (Avantes ULS 2048L; detection range: 350-880 nm; FWHM $1.2 \mathrm{~nm}$; linearity $99.65 \%$, Avantes Inc., Broomfield, CO, USA) fitted with 
an integrating sphere (diameter $152 \mathrm{~mm}$; OL IS-670-LED, Gooch and Housego, Orlando, FL, USA). Data were obtained using the software AvaSoft for Ava Spec-USB2, version 8.0 (Avantes Inc.). The system calibration is traceable to the Bentham spectroradiometer (see above). The combined uncertainty of VBL exitance measurement values was about 7\% (95\% confidence interval) taking into account calibration against Bentham and source area measurements.

\subsection{Photometric and radiometric survey measurements}

Characterisation of stationary lamps, screens and ambient light was performed with a set of portable broadband meters. The repeatability of the survey measurements was $\pm 4 \%$, which complied with EN 14255-1 [26].

\subsection{Illuminance, $E_{\mathrm{V}}$}

Illuminance measurements of domestic lighting sources as well as of ambient indoor and outdoor light conditions were performed with a Hagner universal photometer, model S2 (B. Hagner AB, Solna, Sweden). The illuminance/luminance meter values agreed within $\pm 10 \%$ of the Bentham spectroradiometer measurements.

\subsection{Blue light hazard-weighted irradiance, $E_{b}$}

A portable broadband radiometer was used (PMA2100, Solar Light Company, Inc., Glenside, PA, USA) to obtain $E_{\mathrm{b}}$ of domestic lighting sources as well as of ambient indoor and outdoor light conditions and a dental operating (surgical) light (see Online Resource 1). The radiometer was equipped with a sensor having a spectral responsivity function resembling $B(\lambda)$ (PMA2121 (SN 2894) Analog Blue Light Safety). The expanded uncertainty of the instrument provided by the manufacturer's certificate was 5\% (95\% confidence interval), the uncertainty of comparison of VBL measurements against the Bentham spectroradiometer was $\pm 4 \%$, and combined uncertainty was $7.3 \%$ ( $95 \%$ confidence interval).

\section{6 $E_{\mathrm{b}}$ in relevant illuminance distance}

To compare the selected light sources at a level of illuminance typical of working conditions, values for $E_{\mathrm{b}}$ were calculated per $500 \mathrm{~lx}$. This illuminance value corresponds to the evaluation value for determination of photobiological safety of general lighting service (GLS) lamps according to IEC 62471 [27], an illuminance typically recommended in laboratories and rooms for e.g. office work, physical fitness and childcare (EN 12464-1)[28].

\subsection{Solar UV radiation and VBL exposure}

\subsubsection{Calculation of solar $E_{\mathrm{er}}, E_{\mathrm{b}}$ and $E_{400-500}$}

Outdoor UV irradiances expressed as $E_{\text {er }}$, and VBL exposure expressed as $E_{\mathrm{b}}$ and $E_{400-500}$ were based on radiative transfer modelling, using the libRadtran radiative transfer software package [29]. Modelled data were validated against quality-controlled real-sky data from the Norwegian UV monitoring network (https://github.com/ uvnrpa) [30]. A lookup-table was created for the conversion of UVA irradiance to $E_{\mathrm{b}}$ as a function of SZA and total ozone amount. Calculations of real sky $E_{\mathrm{b}}$ were made for Oslo, Norway (latitude $59^{\circ} 55^{\prime} \mathrm{N}$ ) using ground-based measurement data from 2018 and seasonally daily mean total ozone from overpass data from the ozone monitoring instrument on the Aura spacecraft [31]. Comparison of $E_{\mathrm{b}}$ based on spectral measurements with the Bentham DTM for cloud-free conditions showed close agreement with modelled $E_{\mathrm{b}}$. Similar calculations were made for a tropical site (Dar es Salaam, Tanzania, $6^{\circ} 48^{\prime} \mathrm{S}$ ) and an arctic site (Ny Ålesund, Svalbard, Norway, $78^{\circ} 55^{\prime} \mathrm{N}$ ) (presented as Online resource 2). Moreover, model calculations showed that $\mathrm{E}_{400-500}$ was almost linearly related to $\mathrm{E}_{\mathrm{b}}$ for all SZA, which would justify the use of a constant conversion factor of 1.48 for outdoor conditions and clear sky (Online Resource 3).

\subsubsection{Threshold dose for solar UV exposure}

The threshold dose for solar erythemal UV exposure was set to 1 SED [23] corresponding to an erythemally weighted radiant exposure, $H_{\mathrm{er}}=100 \mathrm{Jm}^{-2}$. The time to reach this radiant exposure was termed $\mathrm{T}_{\mathrm{SED}}$. As the erythemal effective irradiance is highly dependent on the location and time of year (i.e., SZA), calculations were based on cloud-free conditions in Oslo, Norway at winter solstice, vernal equinox and summer solstice.

\subsection{Dose to induce VBL effects in skin}

\subsubsection{Literature search}

A search for articles in scientific journals reporting on visible light effects in skin was performed in PubMed (https://pubmed.ncbi.nlm.nih.gov/) using the search term "blue light skin damage" without limits for year, publication type or language. Articles were excluded if they did not contain information that enabled calculation of radiant exposure. Human, animal and in vitro studies were included. 


\subsubsection{Threshold dose for VBLskin exposure}

Radiant exposure, if not included in the respective studies, was estimated based on reported irradiance and exposure times. The mean of the lowest radiant exposure values reported to induce a biological response in humans and human skin models was calculated, and the time to reach this radiant exposure was termed $\mathrm{T}_{\text {thres}}$.

\section{Results}

\subsection{Literature-based VBL threshold dose for skin}

Fourteen publications reporting on VBL effects in skin and skin models were included. The studies reported induction of a diversity of biological endpoints (Table 1). Effects of a variety of polychromatic light sources emitting in the wavelength range 400-500 $\mathrm{nm}$ resulted in a "lowest observed effect level" corresponding to radiant exposures of between 5 and $200 \mathrm{Jcm}^{-2}$ (Table 1). Induction of observable pigmentation in human skin tissue was reported in four publications [17, 32-34]. This was the only endpoint consistently reported in human skin. The mean of the radiant exposure values reported to induce this endpoint was $65 \mathrm{Jcm}^{-2}$.

\subsection{Time to reach threshold doses}

$T_{\text {thres }}$ for exposure to all domestic lighting sources was longer than 2 weeks (Table 2). $T_{\text {thres }}$ was between 2.5 and 9 months for exposure in front of screens (Table 2).

The $E_{\mathrm{b}}$-values of all the indoor lighting sources were $\leq 50$ $\mu \mathrm{Wcm}^{-2}(500 \mathrm{~lx})^{-1}$ while the corresponding outdoor wintertime value was four times higher (Table 2), reflecting the higher VBL content of the outdoor light spectrum than those of the indoor artificial sources. For outdoor exposure in Oslo, $E_{\mathrm{b}}$ (Fig. 1, Table 2) and $E_{\mathrm{er}}$ (Fig. 1) varied considerably with season and time of day. Correspondingly, $T_{\mathrm{SED}}$ was shorter than $T_{\text {thres }}$ irrespective of the time of day (Fig. 2). The same conclusion holds for both the tropic and arctic examples: In Dar es Salaam, the maximum $E_{\mathrm{b}}$ and $E_{\mathrm{er}}$ values of the year were $33 \%$ and 2.4 times higher, respectively, than in Oslo. In the Svalbard archipelago, the maximum $E_{\mathrm{b}}$ and $E_{\mathrm{er}}$ values of the year were $37 \%$ and $58 \%$ lower, respectively, than in Oslo (Online Resource 2). For detailed measurement values and spectra of the sources, see Online Resource 1 and Online Resource 4, respectively.

\section{3 $\mathrm{T}_{\text {thres }}$ for medical devices}

The irradiance values obtained from commonly used dental material photocuring devices $(n=9)$ varied by a factor seven. Oral tissue or skin exposure with these devices would reach $65 \mathrm{Jcm}^{-2}$ within $<3$ min (Online Resource 1). Blue light emitted from the dental operating light did not reach $65 \mathrm{Jcm}^{-2}$ within a workday (Table 2).

\section{Discussion}

The dose is crucial in determining whether the biological effects (Table 1) represent a health risk or contribute to photoaging under realistic exposure conditions. Different action spectra exist for a diversity of effects induced by optical radiation in various species [44]. The lack of an action spectrum for effects in the skin in the visible wavelength range complicates comparison of the relative efficiency of induction of effects from different light sources. The variable and often inadequate dosimetry of several of the included studies (Table 1) introduced large uncertainties in deriving irradiance and radiant exposure values. For instance, spectral information was not adequately detailed in any of the included studies, and references to the radiometric methods, measurement geometry and instruments (including choice of detectors) were often missing. Presumed VBL effects may have been induced or enhanced from wavelengths outside the VBL range in case of broad spectra. Enhancement of UV-induced photoaging of guinea pig skin by infrared radiation is an example of interaction between different wavelength ranges [12]. Suggested requirements for information about dosimetry in studies of light effects have recently been addressed [45].

Since the studies of skin samples and isolated skin cells (Table 1) reported surface irradiance incident on the samples, we further assume that doses to skin cells within intact skin samples were slightly smaller than the doses received by isolated cells in a cell culture vessel. Thus, the radiant exposure values (Table 1) should not be interpreted as being exact measures of the dose received by cells in the skin. UVA produces 1.5 times more DNA damage in isolated cells than in skin tissue [46], and we assume that a similar difference can exist for VBL. Despite the shortcomings, the doses reported to induce pigmentation of human skin were in the same order of magnitude as those that induced the various endpoints in cells in vitro (Table 1).

The application of $B(\lambda)$, may have underestimated the irradiance for some of the sources. Induction of light effects in the skin is mediated by absorption in various chromophores. Absorption in porphyrins and flavins is likely to occur at visible wavelengths near $400 \mathrm{~nm}$ [16] while melanin and oxyhemoglobin absorption occurs throughout the violet-blue range [33].

The ratio between $B(\lambda)$-weighted and unweighted irradiance of light sources was between 1.41 and 1.61 (calculated from Table 2). The corresponding ratio for outdoor irradiance was within the same range and was almost constant for 


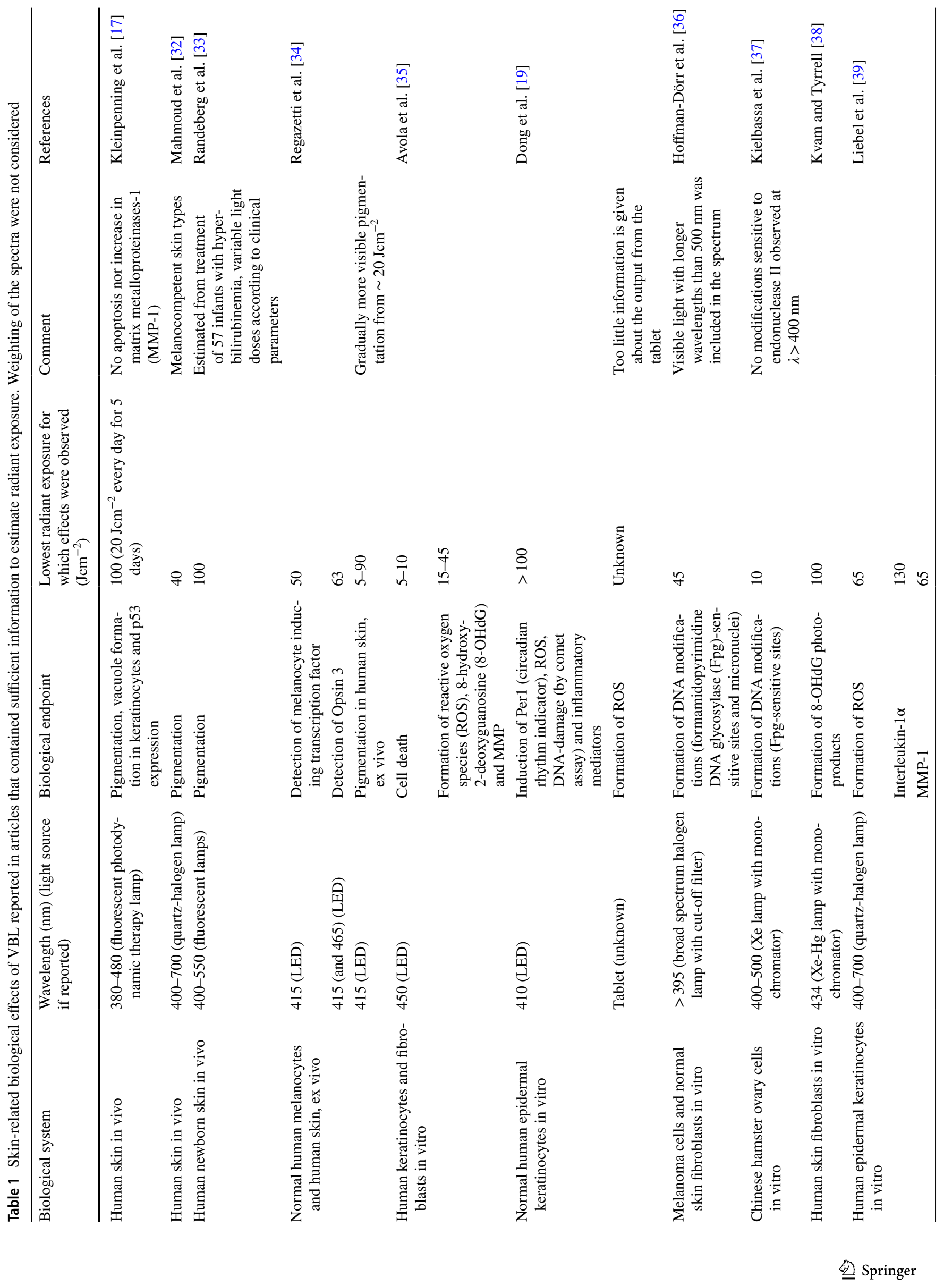




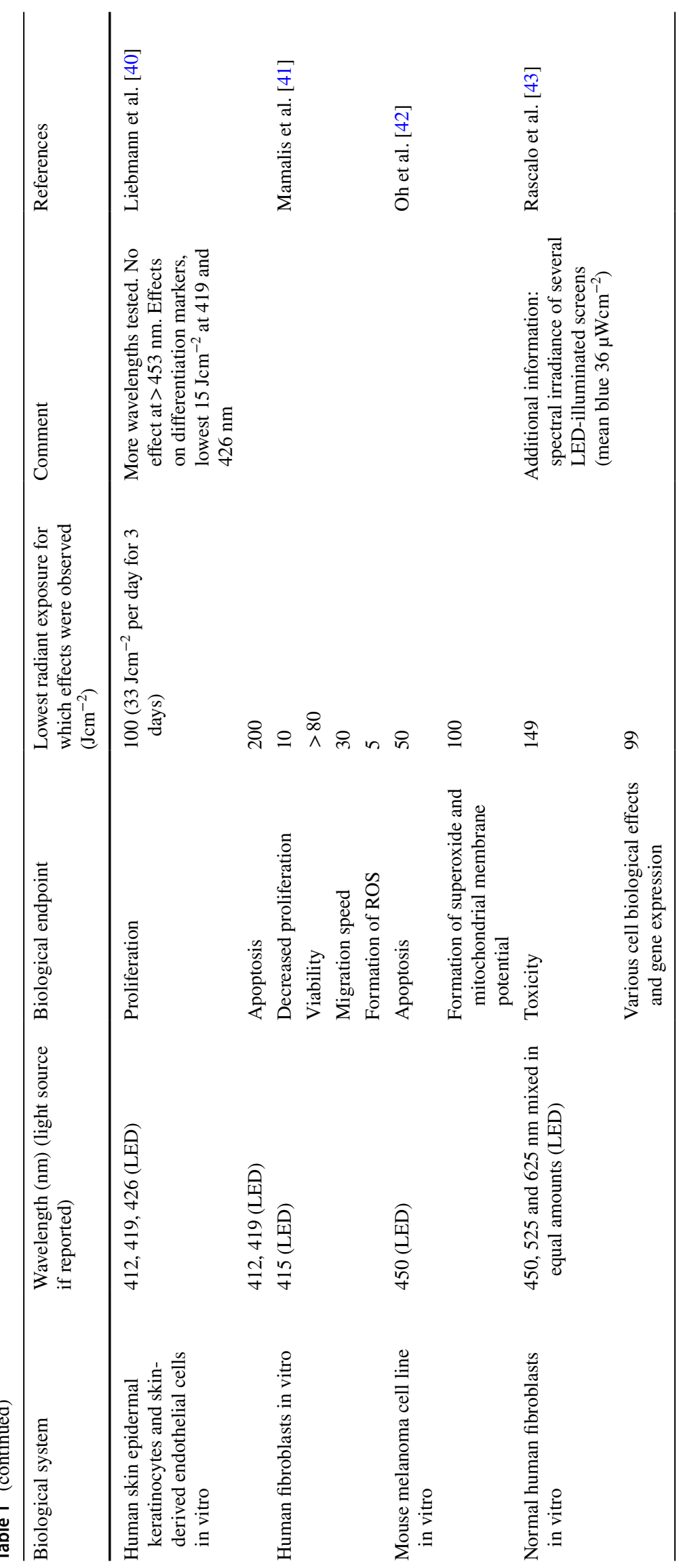


Table 2 Ranges of radiometric and photometric exposure values and corresponding time to reach the estimated lowest radiant exposure $\left(H_{\mathrm{b}}=65\right.$ $\left.\mathrm{Jcm}^{-2}\right)$ to induce a biological effect $\left(T_{\text {thres }}\right)$ for selected light sources and outdoor winter conditions

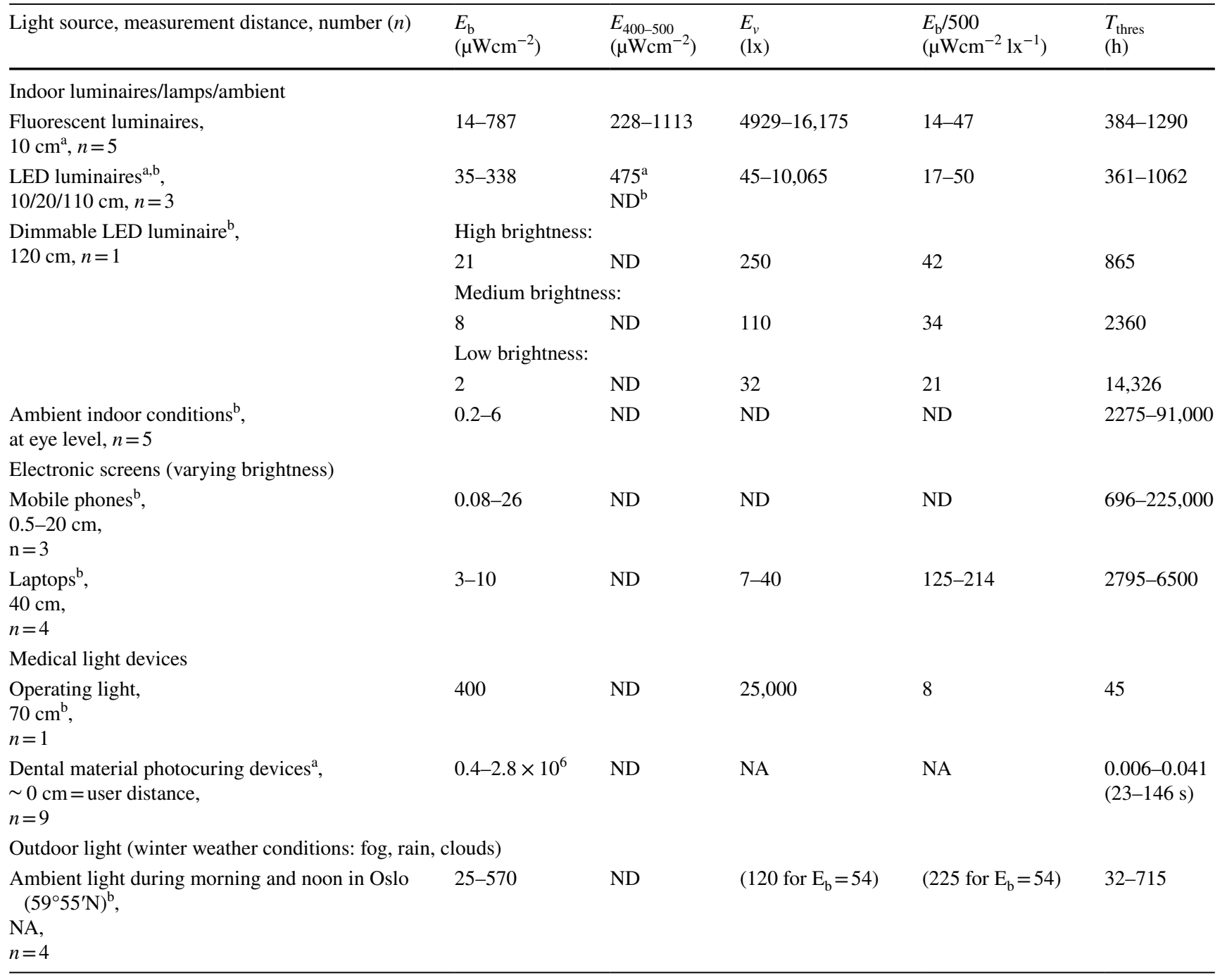

$E_{\mathrm{b}}$ : blue light hazard-weighted irradiance; $E_{400-500}$ : irradiance between 400 and $500 \mathrm{~nm} ; E_{\mathrm{v}}$ : illuminance; $E_{\mathrm{b}} / 500$ : $\mathrm{B}(\lambda)$-weighted irradiance per 500 1x; ND: not determined; NA: not applicable

${ }^{a}$ Laboratory measurement

${ }^{\mathrm{b}}$ Survey measurement. For values and technical details of individual light sources, see Online Resource 1 and Online Resource 4

SZA values between 35 and $90^{\circ}$ (Online Resource 3). We consider these near constant ratios to justify the application of the proxy weighting function. Furthermore, the uncertainty in our exposure data is low compared with that of the literature (Table 1) on which our conclusions are based.

Two studies $[47,48]$ reported on comparison of $B(\lambda)$ weighted radiance of domestic lighting and electronic screens with the relevant limit value for VBL exposure of the retina. All computer monitors and screens from laptops, tablets, and smartphones emitted less than $1 \%$ of the limit value, while the blue sky and domestic lighting emitted between 6 and $60 \%$. Although irradiance rather than radiance is the relevant radiometric quantity to employ for evaluation of optical radiation entering the skin, the ratios between exposure and limit values mentioned above give an impression of the relative differences between the sources. Indicator LEDs often have relatively high radiance because of their limited emission area and angular subtense. This fact can be illustrated by the high irradiances (Online Resource 1) and radiances of LED-based dental material polymerisation devices [49]. Rascalou et al. [43] measured the irradiance and spectral output from eight different LED-based electronic screens. Average irradiance was reported to be about $36 \mu \mathrm{Wcm}^{-2}$ (at unknown distance) between 400 and $490 \mathrm{~nm}$ and at the highest brightness. This value was in the same order of 


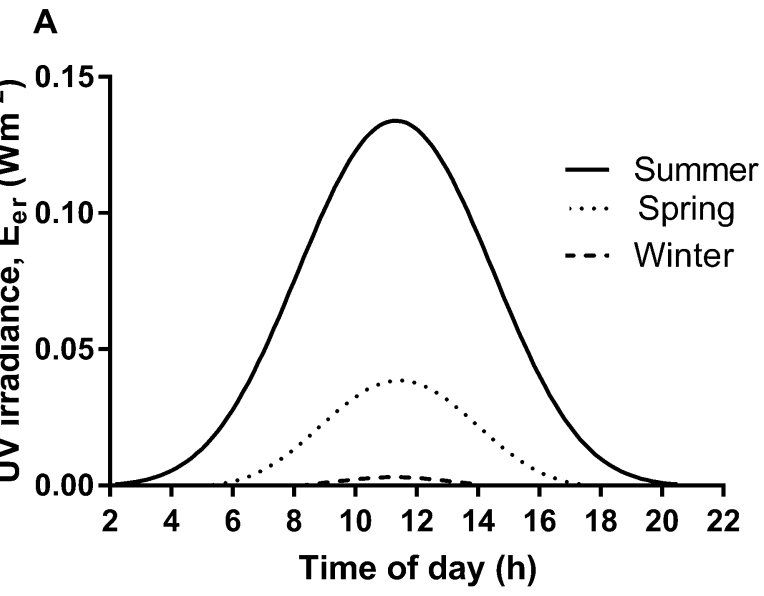

B

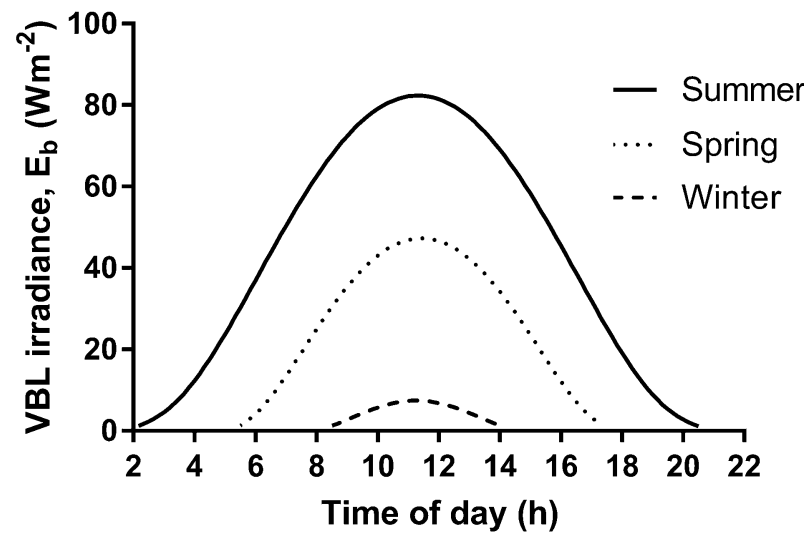

Fig. 1 Plots of clear sky erythemally weighted UV irradiance, $E_{\mathrm{er}}$ (a) and blue light hazard weighted irradiance, $E_{\mathrm{b}}(\mathbf{b})$ as a function of the time of day at vernal equinox (dotted line), summer solstice (solid line) and winter solstice (dashed line). The $E_{\text {er }}$ values were based on modelled data for clear sky conditions in Oslo, Norway. Ozone layer thickness was the seasonally mean value

magnitude as those measured in the current study in normal user position (Table 2).

The included studies (Table 1) did not specify whether the subjects from whom skin or skin cells were obtained had any photodermatoses, other diseases associated with photosensitivity or exposure to photosensitising drugs [50]. Thus, we cannot rule out that photosensitivity may have influenced the nature and degree of effects reported in the included studies. One example of drug-based blue light protection in individuals suffering from a photosensitive disease is the use of afamelanotide in patients with porphyria (see European Medicines Agency, https://www.ema.europa.eu/en/medic ines/human/EPAR/scenesse) [51].

It is uncertain whether intermittent exposure, which represents a likely user exposure situation, will add up to give the same theoretical effects as continuous exposure. The tissue will probably repair a fraction of molecular lesions
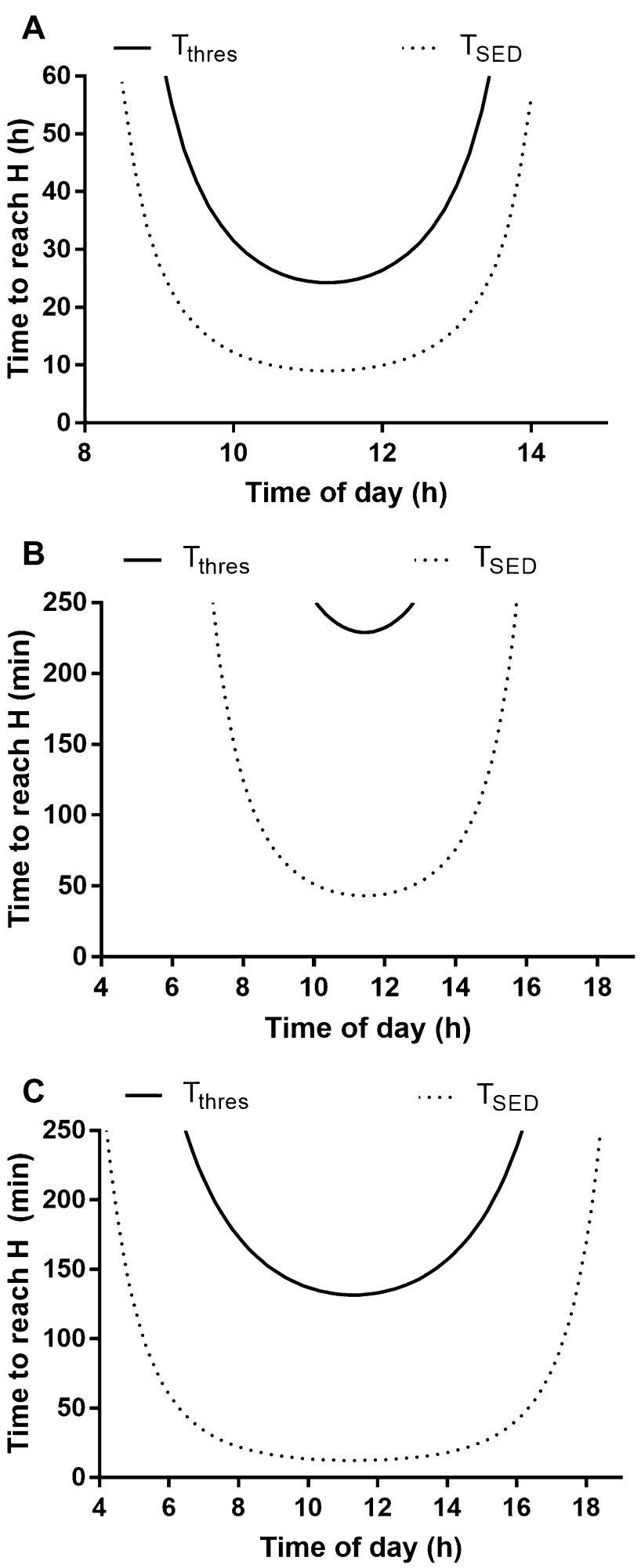

Fig. 2 The time to reach a radiant exposure $(\mathrm{H})$ corresponding to either $1 \mathrm{SED}\left(T_{\mathrm{SED}}\right)$ or a blue light hazard-weighted radiant exposure of $65 \mathrm{Jcm}^{-2}\left(T_{\text {thres }}\right)$ at (a) winter solstice, (b) vernal equinox, and (c) summer solstice based on modelled data for clear sky conditions in Oslo, Norway. Ozone layer thickness was the seasonal mean value 
during dark periods and thereby, prolonging the exposure time before reaching $\mathrm{T}_{\text {thres }}$. The few studies of daily use of electronic screens (see references in Rascalo et al. [43]), report reasonable estimates for frequent users of up to $10 \mathrm{~h}$ per day. Our observations that a minimum continuous exposure in user-distance to screens were in the order of a few thousand hours before any effects were to be expected (Table 2), indicate that the daily exposure is only a small fraction of $T_{\text {thres }}$.

The irradiance of the dental operating light (Table 2) was 8-200 times higher than that of domestic lighting; however, the $T_{\text {thres }}$ of the operating light was several times longer than the longest predicted dental treatment procedure. The emission of dental material light curing devices is up to 1 million times that of, e.g., electronic screens and may potentially induce eye damage within the order of seconds by unintended direct exposure [52]. The short $T_{\text {thres }}$ for skin of $23 \mathrm{~s}$ (Table 2) indicates that irradiating the skin with such devices for prolonged time may cause damage from e.g. local hyperthermia. Since the polymerisation takes place in the oral cavity, exposure of the skin will occur only accidentally. It is uncertain whether oral tissues have similar sensitivity to VBL as skin.

The observation that $T_{\mathrm{SED}}$ was shorter than $T_{\text {thres }}$ all year indicates that a person would become sunburnt before a potential VBL damage would arise. Consequently, at summer solstice in Oslo a person would receive 10 SED from an exposure time corresponding to $T_{\text {thres }}$. For most people this dose would imply visible skin damage, see e.g. McKenzie and Lucas [53]. Even in the unlikely case that a person uses a $100 \%$ effective UV sunscreen, the $T_{\text {thres }}$ would be longer than $2 \mathrm{~h}$ in the middle of the day (Fig. 2). Point irradiance values were used to calculate theoretical values of $T_{\mathrm{SED}}$ and $T_{\text {thres }}$, ignoring the fact that the irradiance is not constant and quickly drops after solar noon. Therefore, in reality, $\mathrm{T}_{\text {thres }}$ would be extended beyond $2 \mathrm{~h}$. At mid-winter in Oslo, the daily erythemally weighted UV dose never reaches 1 SED, indicating that the comparison of maximum exposure times is not relating to realistic exposure conditions. The ratios between estimated $T_{\mathrm{SED}}$ and $T_{\text {thres }}$ at noon were 1/10, 1/5 and $1 / 3$ at summer solstice, spring equinox and winter solstice, respectively. The reason for this difference is that the atmosphere absorbs and scatters UV and VBL to different extents.

\section{Conclusions}

Based on literature studies, exposure assessments and unknown weighting functions for skin effects, we conclude the following: VBL emission doses from selected domestic sources, electronic screens and a medical operating light were lower than doses reported to induce observable effects in the skin within practical exposure times. The UV component of solar radiation caused skin damage in shorter time than that of VBL. Thus, application of VBL-absorbing sunscreens is not needed. Exceptions may be for patients suffering from photosensitive diseases or taking photosensitising medication.

Supplementary Information The online version contains supplementary material available at https://doi.org/10.1007/s43630-021-00043-9.

Acknowledgements The authors would like to express their gratitude to the following: Mr. Tommy Nakken Aalerud, previous employee of DSA for performing some of the optical measurements on dental polymerisation devices; Dr. Aida Mulic, NIOM for assistance in performing a clinically relevant light emission measurement of an operating light unit; the Institute of Clinical Dentistry, University of Oslo for access to the operating light; Prof. Emeritus Anders Johnsson, Department of Physics, Norwegian University of Science and Technology for discussions.

Funding Open access funding provided by University of South-Eastern Norway. (information that explains whether and by whom the research was supported) No external funding.

Code availability (software application or custom code) Not applicable.

\section{Declarations}

Conflict of interest (include appropriate disclosures) No conflicts of interest declared.

Ethics approval (include appropriate approvals or waivers) Not applicable.

Consent to participate (include appropriate statements) Not applicable.

Consent for publication (include appropriate statements) Not applicable.

Availability of data and material (data transparency) All data generated or analysed during this study are included in this published article [and its supplementary information files].

Open Access This article is licensed under a Creative Commons Attribution 4.0 International License, which permits use, sharing, adaptation, distribution and reproduction in any medium or format, as long as you give appropriate credit to the original author(s) and the source, provide a link to the Creative Commons licence, and indicate if changes were made. The images or other third party material in this article are included in the article's Creative Commons licence, unless indicated otherwise in a credit line to the material. If material is not included in the article's Creative Commons licence and your intended use is not permitted by statutory regulation or exceeds the permitted use, you will need to obtain permission directly from the copyright holder. To view a copy of this licence, visit http://creativecommons.org/licenses/by/4.0/.

\section{References}

1. Allen (2017) Is our tech addiction ruining our skin? Put down your phone \& pick up your SPF - your skin is in trouble. 
Glomourmagazine Aug. 16, 2016. https://www.glamourmagazine. co.uk/article/hev-rays-skincare. Accessed 10 May 2020.

2. Campiche, R., Curpen, S. J., Lutchmanen-Kolanthan, V., Gougeon, S., Cherel, M., Laurent, G., et al. (2020). Pigmentation effects of blue light irradiation on skin and how to protect against them. International Journal of Cosmetic Science, 42(4), 399-406. https://doi.org/10.1111/ics.12637

3. Lyons, A. B., Trullas, C., Kohli, I., Hamzavi, I. H., \& Lim, H. W. Photoprotection beyond ultraviolet radiation: A review of tinted sunscreens. Journal of the American Academy of Dermatology. https://doi.org/10.1016/j.jaad.2020.04.079.

4. Zastrow, L., \& Lademann, J. (2016). Light - instead of UV protection: new requirements for skin cancer prevention. Anticancer Research, 36(3), 1389-1393

5. SCHEER (2018). Opinion on Potential risks to human health of Light Emitting Diodes (LEDs). Brussels.

6. ANSES (2019). OPINION of the French Agency for Food, Environmental and Occupational Health \& Safety on the "effects on human health and the environment (fauna and flora) of systems using light-emitting diodes (LEDs)". Maisons-Alfort Cedex.

7. Shanbhag, S., Nayak, A., Narayan, R., \& Nayak, U. Y. (2019). Anti-aging and sunscreens: Paradigm shift in cosmetics. Advanced Pharmaceutical Bulletin, 9(3), 348-359. https://doi.org/10.15171/ apb.2019.042

8. Schalka, S., de Paula Correa, M., Sawada, L. Y., Canale, C. C., \& de Andrade, T. N. (2019). A novel method for evaluating sun visible light protection factor and pigmentation protection factor of sunscreens. Clinical, Cosmetic and Investigational Dermatology, 12, 605-616. https://doi.org/10.2147/CCID.S207256

9. Wabnik, M., Kockott, D., Garbe, B., Theek, C., Heinrich, U., Tronnier, H., et al. (2019). Application of an easy-to-perform high-energy and low-end visible light transmittance method and the influence of tinted sunscreens on high-energy/low-end visible light transmittance and infrared protection. Skin Pharmacology Physiology, 32(5), 244-253. https://doi.org/10.1159/000501131

10. ICNIRP (2004). Guidelines on limits of exposure to ultraviolet radiation of wavelengths between $180 \mathrm{~nm}$ and $400 \mathrm{~nm}$ (incoherent optical radiation). Health Physics, 87(2), 171-186. https://doi.org/ 10.1097/00004032-200408000-00006

11. Schroeder, P., Schieke, S. M., \& Morita, A. (2006). Premature skin aging by infrared radiation, tobacco smoke and ozone. In B. A. Gilchrest \& J. Krutmann (Eds.), Skin Aging. (pp. 45-53). Berlin, Heidelberg: Springer.

12. Kligman, L. H. (1982). Intensification of ultraviolet-induced dermal damage by infrared radiation. Archives of Dermatological Research, 272, 229-238

13. Kligman, L. H., \& Kligman, A. M. (1986). The nature of photoaging: its prevention and repair. Photo-Dermatology, 3(4), 215-227

14. Pathak, M. A., Riley, F. C., \& Fitzpatrick, T. B. (1962). Melanogenesis in human skin following exposure to long-wave ultraviolet and visible light. The Journal of Investigative Dermatology, 39, 435-443

15. Spikes, J. D. (1989). Photosensitization. In K. C. Smith (Ed.), The Science of Photobiology. (pp. 79-110). New York: Plenum Press.

16. Mahmoud, B. H., Hexsel, C. L., Hamzavi, I. H., \& Lim, H. W. (2008). Effects of visible light on the skin. Photochemistry and Photobiology, 84(2), 450-462. https://doi.org/10.1111/j.17511097.2007.00286.x

17. Kleinpenning, M. M., Smits, T., Frunt, M. H., van Erp, P. E., van de Kerkhof, P. C., \& Gerritsen, R. M. (2010). Clinical and histological effects of blue light on normal skin. Photodermatology, Photoimmunology and Photomedicine, 26(1), 16-21. https://doi. org/10.1111/j.1600-0781.2009.00474.x
18. Sondenheimer, K., \& Krutmann, J. (2018). Novel Means for Photoprotection. Front Medicine (Lausanne), 5, 162. https://doi.org/ 10.3389/fmed.2018.00162

19. Dong, K., Goyarts, E. C., Pelle, E., Trivero, J., \& Pernodet, N. (2019). Blue light disrupts the circadian rhythm and create damage in skin cells. International Journal of Cosmetic Science, 41(6), 558-562. https://doi.org/10.1111/ics.12572

20. Narla, S., Kohli, I., Hamzavi, I. H., \& Lim, H. W. (2020). Visible light in photodermatology. Photochemical \& Photobiological Sciences, 19(1), 99-104. https://doi.org/10.1039/c9pp00425d

21. IARC (2020). Monographs on the identification of carcinogenic hazards to humans. https://monographs.iarc.fr/list-of-classifica tions. Accessed 16 April 2020.

22. ICNIRP (2013). ICNIRP Guidelines on limit of exposure to incoherent visible and infrared radiation. Health Physics, 105(1), 74-96. https://doi.org/10.1097/HP.0b013e318289a611.

23. ISO, CIE. (1999). ISO $17166 /$ CIE S007: Erythema reference action spectrum and standard erythema dose. Vienna: CIE Central Bureau.

24. Williamson, S. J., Cummins, H.Z. (1983). Light and Color in Nature and Art. Wiley.

25. Hulsen, G., Grobner, J., Nevas, S., Sperfeld, P., Egli, L., Porrovecchio, G., et al. (2016). Traceability of solar UV measurements using the Qasume reference spectroradiometer. Applied Optics, 55(26), 7265-7275. https://doi.org/10.1364/ao.55.007265

26. CEN (2005). EN 14255-2 : Measurement and assessment of personal exposures to incoherent optical radiation - Part 2: Visible and infrared radiation emitted by artificial sources in the workplace. Brussels.

27. IEC (2006). IEC 62471 Photobiological safety of lamps and lamp systems. Geneva.

28. CEN (2011). EN 12464-1 Light and lighting, Lighting of work places, Part 1: Indoor work places. Brussels.

29. Mayer, B., \& Kylling, A. (2005). Technical note: The libRadtran software package for radiative transfer calculations-description and examples of use. Atmospheric Chemistry and Physics, 5, $1855-1877$

30. DSA (2020). UVNRPA, dose data from the Norwegian UV-network, Norwegian Radiation and Nuclear Safety Authority (DSA). https://github.com/uvnrpa. Accessed 11 May 2020.

31. NASA (2020). Aura Validation Data Center. https://avdc.gsfc. nasa.gov. Accessed 11 May 2020.

32. Mahmoud, B. H., Ruvolo, E., Hexsel, C. L., Liu, Y., Owen, M R., Kollias, N., et al. (2010). Impact of long-wavelength UVA and visible light on melanocompetent skin. The Journal of Investigative Dermatology, 130(8), 2092-2097. https://doi.org/10.1038/jid. 2010.95

33. Randeberg, L. L., Roll, E. B., Nilsen, L. T., Christensen, T., \& Svaasand, L. O. (2005). In vivo spectroscopy of jaundiced newborn skin reveals more than a bilirubin index. Acta Paediatrica, 94(1), 65-71. https://doi.org/10.1111/j.1651-2227.2005.tb01790.x

34. Regazzetti, C., Sormani, L., Debayle, D., Bernerd, F., Tulic, M. K., De Donatis, G. M., et al. (2018). Melanocytes sense blue light and regulate pigmentation through Opsin-3. The Journal of Investigative Dermatology, 138(1), 171-178. https://doi.org/10.1016/j. jid.2017.07.833

35. Avola, R., Graziano, A. C. E., Pannuzzo, G., Bonina, F., \& Cardile, V. (2019). Hydroxytyrosol from olive fruits prevents bluelight-induced damage in human keratinocytes and fibroblasts. Journal of Cellular Physiology, 234(6), 9065-9076. https://doi. org/10.1002/jcp.27584

36. Hoffmann-Dorr, S., Greinert, R., Volkmer, B., \& Epe, B. (2005). Visible light $(>395 \mathrm{~nm}$ ) causes micronuclei formation in mammalian cells without generation of cyclobutane pyrimidine dimers. 
Mutation Research, 572(1-2), 142-149. https://doi.org/10.1016/j. mrfmmm.2005.01.011

37. Kielbassa, C., Roza, L., \& Epe, B. (1997). Wavelength dependence of oxidative DNA damage induced by UV and visible light. Carcinogenesis, 18(4), 811-816. https://doi.org/10.1093/carcin/ 18.4.811

38. Kvam, E., \& Tyrrell, R. M. (1997). Induction of oxidative DNA base damage in human skin cells by UV and near visible radiation. Carcinogenesis, 18(12), 2379-2384. https://doi.org/10.1093/ carcin/18.12.2379

39. Liebel, F., Kaur, S., Ruvolo, E., Kollias, N., \& Southall, M. D. (2012). Irradiation of skin with visible light induces reactive oxygen species and matrix-degrading enzymes. The Journal of Investigative Dermatology, 132(7), 1901-1907. https://doi.org/10. 1038/jid.2011.476

40. Liebmann, J., Born, M., \& Kolb-Bachofen, V. (2010). Blue-light irradiation regulates proliferation and differentiation in human skin cells. The Journal of Investigative Dermatology, 130(1), 259-269. https://doi.org/10.1038/jid.2009.194

41. Mamalis, A., Garcha, M., \& Jagdeo, J. (2015). Light emitting diode-generated blue light modulates fibrosis characteristics: Fibroblast proliferation, migration speed, and reactive oxygen species generation. Lasers in Surgery and Medicine, 47(2), 210-215. https://doi.org/10.1002/lsm.22293

42. Oh, P. S., Na, K. S., Hwang, H., Jeong, H. S., Lim, S., Sohn, M. H., et al. (2015). Effect of blue light emitting diodes on melanoma cells: Involvement of apoptotic signaling. Journal of Photochemistry and Photobiology B: Biology, 142, 197-203. https://doi.org/ 10.1016/j.jphotobiol.2014.12.006

43. Rascalou, A., Lamartine, J., Poydenot, P., Demarne, F., \& Bechetoille, N. (2018). Mitochondrial damage and cytoskeleton reorganization in human dermal fibroblasts exposed to artificial visible light similar to screen-emitted light. Journal of Dermatological Science. https://doi.org/10.1016/j.jdermsci.2018.04.018

44. Gorton (2010). Biological Action Spectra, Holly L. Gorton in Photobiological Sciences on-line. http://photobiology.info/Gorton. html. Accessed 11 May 2020.

45. Spitschan, M., Stefani, O., Blattner, P., Gronfier, C., Lockley, S. W., \& Lucas, R. J. (2019). How to report light exposure in human chronobiology and sleep research experiments. Clocks Sleep, 1(3), 280-289. https://doi.org/10.3390/clockssleep1030024

46. Mouret, S., Baudouin, C., Charveron, M., Favier, A., Cadet, J., \& Douki, T. (2006). Cyclobutane pyrimidine dimers are predominant DNA lesions in whole human skin exposed to UVA radiation. Proceedingd of National Academy Science of United States of America, 103(37), 13765-13770. https://doi.org/10.1073/pnas. 0604213103

47. O’Hagan, J. B., Khazova, M., \& Price, L. L. (2016). Low-energy light bulbs, computers, tablets and the blue light hazard. Eye (London, England), 30(2), 230-233. https://doi.org/10.1038/eye.2015. 261

48. Bullough, J. D., Bierman, A., \& Rea, M. S. (2019). Evaluating the blue-light hazard from solid state lighting. International Journal of Occupational Safety and Ergonomics, 25(2), 311-320. https:// doi.org/10.1080/10803548.2017.1375172

49. Bruzell, E. M., Christensen, T., \& Johnsen, B. (2015). Sufficient $\varnothing j e n b e s k y t t e l s e$ reducerer risikoen for $\varnothing$ jenskader fra hærdelamper (Appropriate eye protection filters prevent ocular damage from curing light). [Research article]. Tandlaegebladet, 119(5), $368-378$.

50. Ibbotson, S. (2018). Drug and chemical induced photosensitivity from a clinical perspective. Photochemical \& Photobiological Sciences, 17(12), 1885-1903. https://doi.org/10.1039/c8pp00011e

51. EMA (2014). European public assessment report (EPAR) for Scenesse. https://www.ema.europa.eu/en/medicines/human/EPAR/ scenesse. Accessed 11 May 2020.

52. Bruzell, E. M., Johnsen, B., Aalerud, T. N., \& Christensen, T. (2007). Evaluation of eye protection filters for use with dental curing and bleaching lamps. Journal of Occupational and Environmental Hygiene, 4(6), 432-439. https://doi.org/10.1080/15459 620701354218

53. McKenzie, R. L., \& Lucas, R. M. (2018). Reassessing impacts of extended daily exposure to low level solar UV radiation. Science and Reports, 8(1), 13805. https://doi.org/10.1038/ s41598-018-32056-3 